\title{
Coupling coefficient, hierarchical structure, and earthquake cycle for the source area of the 2011 off the Pacific coast of Tohoku earthquake inferred from small repeating earthquake data
}

\author{
Naoki Uchida and Toru Matsuzawa \\ Graduate School of Science, Tohoku University, Sendai 980-8578, Japan \\ (Received April 29, 2011; Revised July 8, 2011; Accepted July 10, 2011; Online published September 27, 2011)
}

\begin{abstract}
We have estimated the spatial distribution of interplate coupling in and around the source area for the 2011 Tohoku earthquake from small repeating earthquake data. The source area of the 2011 Tohoku earthquake exhibited a relatively high coupling coefficient $(>0.5)$ for the period from 1993 to 2007 and was surrounded by areas of low coupling $(<0.5)$ at its western (down-dip), northern and southern extents. These low-coupling areas probably prevented further propagation of the mainshock rupture. A high coupling coefficient is estimated even near the trench that can act as the source of the large tsunami of the present earthquake. The averaged seismic coupling of $0.5-0.8$ in the $M 9$ earthquake's source area and the seismic moment of the earthquake suggest that the slip deficit for the $M 9$ earthquake was accumulated over a period of 260-880 years, consistent with the recurrence interval of such great earthquakes from tsunami deposit data. It also suggests that the several $M \sim 7$ earthquakes which have occurred in the source area since 1926 were minor events that released only a part of the accumulated strain energy. The hierarchical structure of asperities, as in the case of the Kamaishi sequence, may be the key to understanding huge earthquakes that encompass several smaller asperities.
\end{abstract}

Key words: Repeating earthquake, asperity, subduction zone, earthquake cycle, interplate earthquake.

\section{Introduction}

The 2011 Tohoku earthquake ( $M 9.0$ ) occurred in the NE Japan subduction zone along the Japan Trench. The earthquake ruptured a very wide area $(\geq 400 \mathrm{~km} \times 150 \mathrm{~km})$ along the trench in a region that has experienced many $M \sim 7$ earthquakes since 1926 (Fig. 1). Why such a great earthquake and the accompanying tsunami occurred in this subduction zone and why its rupture did not further extend from the present slip area are important questions for understanding the generation mechanism of the earthquake. The relationship with a large tsunamigenic earthquake with a recurrence interval of 400-1300 years from geological data (e.g., Minoura and Nakaya, 1991; Sawai et al., 2007) is also important.

In addition, the re-rupture of $M \sim 7$ slip areas (asperities) of previous earthquakes by the $M 9$ earthquake cannot be explained using a simple model in which an asperity patch in an aseismically slipping region undergoes recurrent seismic rupture in the same manner. No $M 8$ asperities had been known in this area before the occurrence of the $M 9$ event. Therefore, it is not likely to be the rupture of multiple $M 8$ asperities. The structure of asperities that produced the $M 9$ earthquake is not yet known.

To address these questions, we estimate the interplate coupling coefficient in and around the source area of the

Copyright (C) The Society of Geomagnetism and Earth, Planetary and Space Sciences (SGEPSS); The Seismological Society of Japan; The Volcanological Society of Japan; The Geodetic Society of Japan; The Japanese Society for Planetary Sciences; TERRAPUB.

doi:10.5047/eps.2011.07.006
2011 Tohoku earthquake using data from small repeating earthquakes, and discuss its rupture mode.

\section{Data and Method}

The dataset and method used in the present study are similar to Uchida et al. (2009), in which interplate coupling was analyzed at the southernmost part of the NE Japan subduction zone. We use digital seismograms recorded by the microearthquake observation network of the Tohoku University, for the period from 1993 to March, 2007. This time period does not include the four years before the 2011 earthquake and the years before 1993. However, we consider that the considered time period (13 years) is long enough to estimate the average coupling coefficient and we assume it shows the typical coupling distribution existing before the 2011 Tohoku earthquake.

Seismograms of shallow (depth $<95 \mathrm{~km}$ ) earthquakes with magnitudes of 2.5 or larger are used in the analysis. The sampling frequency is $100 \mathrm{~Hz}$ and most of the seismometers are $1 \mathrm{~Hz}$ velocity-type instruments. The coherence of the waveforms for all event pairs with epicentral separations of less than $30 \mathrm{~km}$ are calculated. The time windows for seismogram analysis are set at $0-40 \mathrm{~s}$ from the $P$-wave arrival times. Two earthquakes are considered to represent a repeating pair if the average coherence at 1 , $2,3,4,5,6,7$, and $8 \mathrm{~Hz}$ is larger than 0.95 at two or more stations. A pair (group) of repeaters is linked with another pair (group) if the two pairs (groups) share an earthquake in common.

We identify 3234 small repeating earthquakes (876 groups of repeating sequences) with magnitudes of 2.5 to 


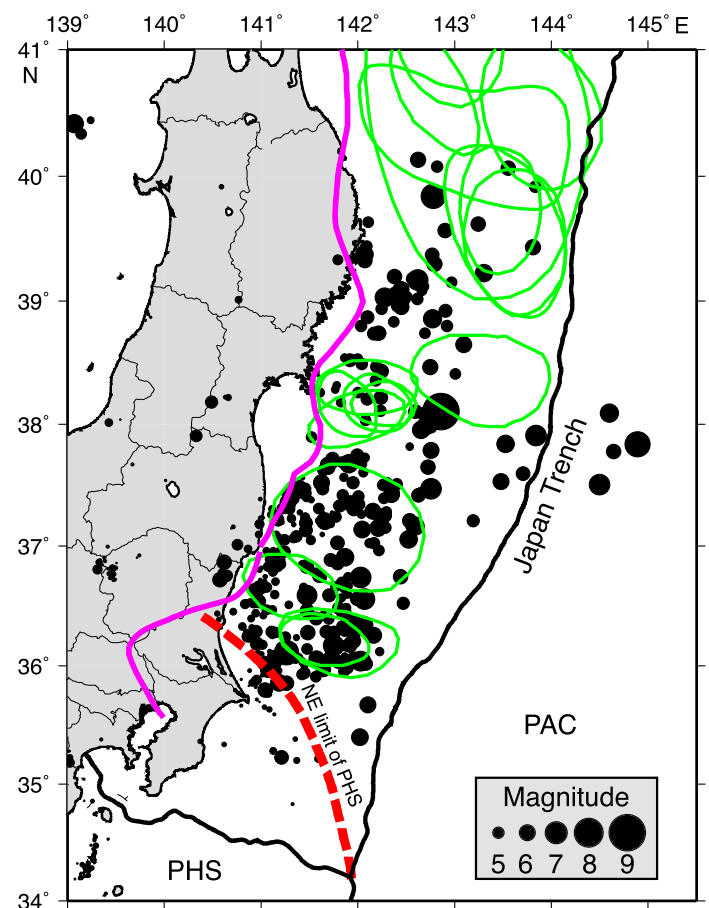

Fig. 1. Hypocenters of mainshock and aftershocks in a 24-hour period for the 2011 Tohoku earthquake (black circles) and aftershock areas for $M \geq 7$ earthquakes since 1926 (green lines, Uchida et al., 2009). Hypocenter data are from the Japan Meteorological Agency. Red dashed line shows down-dip limit of the Philippine Sea Plate (Uchida et al., 2009). Thick pink line shows the western limit of interplate earthquake distribution from Igarashi et al. (2001) and Uchida et al. (2009).

4.8 for the period from 1993 to March 2007. Repeating earthquakes in the Kanto region are classified into two groups that occurred at the upper surfaces of the Philippine Sea Plate (PHS) and the Pacific Plate (PAC) based on their depths, as shown in Uchida et al. (2009). Only the repeating earthquakes at the upper surface of the PAC are plotted in Fig. 2 with black dots and used in this paper.

The slip for each small repeating earthquake is estimated based on the following relationship between the seismic moment $\left(M_{\mathrm{o}}\right.$; dyne.cm) and fault slip $(d ; \mathrm{cm})$, proposed by Nadeau and Johnson (1998).

$$
\log (d)=-2.36+0.17 \log \left(M_{\mathrm{o}}\right)
$$

The scalar moment for each event is estimated from the magnitude determined by the Japan Meteorological Agency (JMA) using the relationship between magnitude and scalar moment proposed by Hanks and Kanamori (1979). The slip rate $(v)$ is estimated from the cumulative slip of each small repeating earthquake group and the time period of the data analysis. Then, using the plate convergence rate $\left(v_{0}\right)$ and the slip rate $(v)$, the coupling coefficient $(c)$ in this region is calculated as follows:

$$
c=\left(v_{0}-v\right) / v_{0}
$$

A coupling coefficient of zero indicates that the fault is creeping at its long-term rate, whereas a value of 1 indicates that it is fully locked and is thus accumulating strain energy that will be released in future earthquakes or episodic creep. The plate convergence rate $\left(v_{0}\right)$ between the PAC and PHS

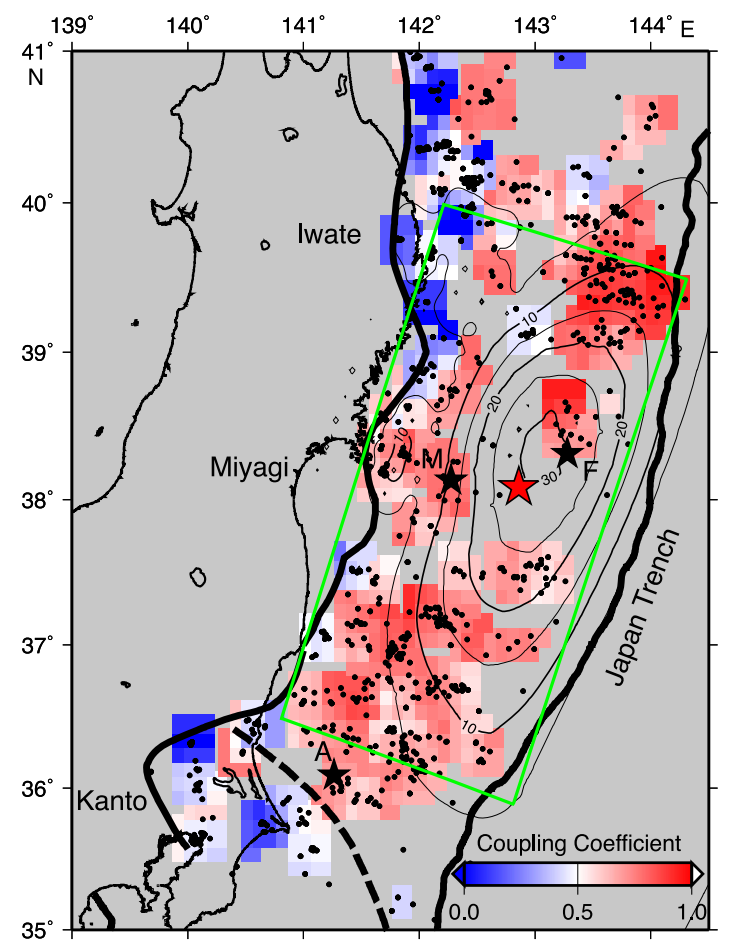

Fig. 2. Interplate coupling coefficient estimated from small repeating earthquakes for the period from 1993 to March 2007 (color). Distribution of small repeating earthquakes (black dots) and coseismic slip area (contours, Iinuma et al. (2011)) are also shown in this figure. Bold lines denote the down-dip limit of interplate earthquakes (Igarashi et al., 2001; Uchida et al., 2009) and the trench axis. Dashed bold line denotes northeastern limit of the Philippine Sea plate (Uchida et al., 2009). The averaged coupling coefficient is estimated for every $0.3 \mathrm{de}-$ gree by 0.3 degree windows that have three or smaller repeating earthquake groups. The red star indicates the hypocenter of the 2011 Tohoku earthquake. Stars marked by M, F and A indicate the hypocenter of the 2005 Miyagi-oki earthquake ( $M 7.2)$, the $M 7.3$ earthquake on March 9, 2011 and the largest aftershock on March 11, 2011 (M 7.7), respectively.

is set to $5.1 \mathrm{~cm} / \mathrm{yr}$, and $7.2 \mathrm{~cm} / \mathrm{yr}$ between the PAC and the overriding plate (Sella et al., 2002). We estimate the interplate coupling coefficients on the PAC at the location of each small repeating earthquake group and average them within a moving spatial window of 0.3 by 0.3 degrees.

\section{Spatial Distribution of Interplate Coupling}

The small repeating earthquakes are thought to occur at small asperities on the plate boundary, allowing them to catch up with the surrounding region, which is undergoing aseismic slip. Therefore, the distribution of a small repeating earthquake sequence contains information on the state of interplate coupling. The occurrence of repeating earthquakes indicates that the plate boundary around a seismic patch is creeping. In contrast, the absence of such repeating earthquakes indicates that the plates are either fully coupled or no seismic patches exist at the boundary (fully decoupled). The anti-correlation between the coseismic slip area for large interplate earthquakes and small repeating earthquakes has been previously pointed out (e.g., Uchida et al., 2003). In the region where a large amount of coseismic slip was estimated to have occurred during the 2011 Tohoku earthquake (Iinuma et al., 2011, Fig. 2), the density of small 
repeating earthquake groups is also small.

For the areas in which small repeating earthquakes occur, the spatial distribution of the interplate coupling coefficient before the 2011 Tohoku earthquake is shown in Fig. 2 on a color scale. To estimate the uncertainty of the coupling coefficient, we calculated the effect of one repeating earthquake missing in a group. This is because whether one repeating earthquake is included or not can make difference in the estimations of slip rate and coupling. From the average slip amount of a repeating earthquake $(17.1 \mathrm{~cm})$ and slip deficit for the study period $(104 \mathrm{~cm})$ the difference in the coupling coefficient estimated with, and without, one repeating earthquake is 0.16 . Since the minimum number of groups used for the coupling estimation is three, the uncertainty of the coupling coefficient is smaller than 0.1 . The area where coseismic slip occurred seems to have a relatively high coupling coefficient. As suggested by Uchida et al. (2009), the seismic coupling coefficient to the south of the NE limit of the PHS (the contact zone between the PHS and PAC) is not large $(\sim 0.3)$ and the seismic slip did not intrude into this region. The largest aftershock ( $M 7.7$, indicated by the black star in Fig. 2) also occurred to the north of the limit. The area close to the down-dip limit of the interplate earthquake (black line) and the off-Iwate region $\left(39^{\circ}-40^{\circ} \mathrm{N}\right)$ also has a relatively low coupling coefficient and seismic slip of the 2011 Tohoku earthquake is not considered to have occurred in this area. These low-coupling areas probably prevented further propagation of the mainshock rupture.

On the other hand, the up-dip area of the fault (the area close to the Japan trench) is seen to have a relatively-high coupling coefficient despite the fact that coupling has previously been assumed to be low due to the existence of unconsolidated sediment (e.g., Oleskevich et al., 1999). This near-trench region is far from the land GPS stations and it is difficult to resolve the coupling coefficient in this region precisely from the GPS data alone. It is possible that slip in this high-coupling area contributed to the generation of the large tsunami accompanying the 2011 Tohoku earthquake (e.g., Fujii et al., 2011; Maeda et al., 2011).

\section{Interplate Coupling and Earthquake Cycle for the $M 9$ Source Area}

The northeastern Japan subduction zone was considered to have a low seismic coupling (10-30\%) based on the cumulative seismic moment over the past $\sim 100$ years (e.g., Peterson and Seno, 1984; Pacheco et al., 1993). However, GPS data analyses in the recent 5-7 years (e.g., Nishimura et al., 2004; Suwa et al., 2006; Hashimoto et al., 2009) have indicated a higher interplate coupling in this area (50$120 \%)$. The interplate coupling for the past 14 years from small repeating earthquakes is also found to be higher (an average value of about $66 \%$ in the rectangle in Fig. 2). Therefore, there are discrepancies between the observed seismic moment release and the estimated seismic coupling from geodetic and small repeating earthquake data. However, if we take into account the M9 2011 Tohoku earthquake, the seismic coupling estimated from seismic moment release data will become larger than the previous estimates. The seismic moment of the 2011 Tohoku earthquake

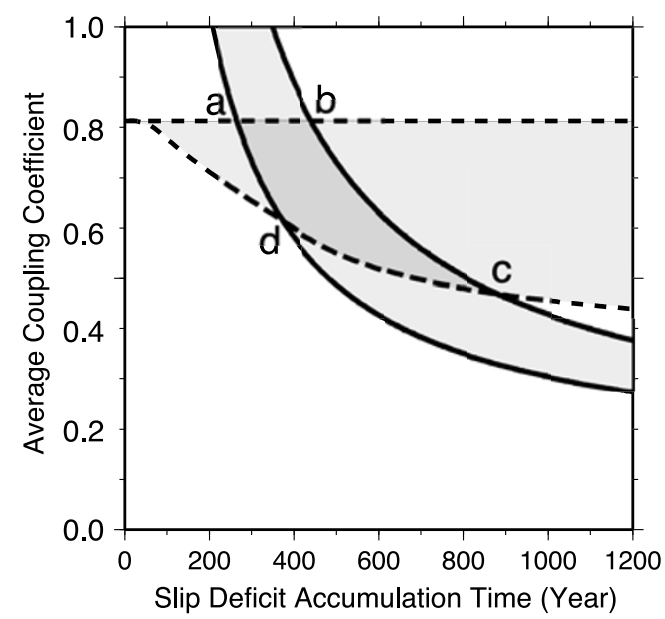

Fig. 3. Relationship between the average coupling coefficient and the slip deficit accumulation time. Black solid lines indicate lower and upper bounds from the moment budget of accumulation in the interseismic period and release in the coseismic and afterslip period. Dashed lines indicate lower and upper bounds of the averaged coupling coefficient from our study. The dark gray area $(\mathrm{a}-\mathrm{b}-\mathrm{c}-\mathrm{d})$ shows the probable range of the averaged coupling coefficient and the length of the interseismic period.

accounts for about $93 \%$ of the cumulative moment, from 1926 to March 2011, in the source area.

Based on the seismic coupling coefficient in this study, we try to estimate the slip deficit accumulation time ( $T$, hereafter the length of the interseismic period) of the 2011 Tohoku earthquake. First, we equalize the accumulated moment deficit before the 2011 Tohoku earthquake and the moment release of the coseismic slip $\left(M_{\mathrm{o}}^{\mathrm{c}}=4.0 \times 10^{22} \mathrm{~N} \mathrm{~m}\right)$ and afterslip $\left(M_{\mathrm{o}}^{\mathrm{a}}\right)$ of the 2011 Tohoku earthquake,

$$
\mu \cdot C \cdot v_{0} \cdot T \cdot S-\dot{M}_{\mathrm{o}} \cdot T=M_{\mathrm{o}}^{\mathrm{c}}+M_{\mathrm{o}}^{\mathrm{a}} \cdot
$$

Here, $\mu$ is the rigidity $\left(=4.0 \times 10^{10} \mathrm{~N} / \mathrm{m}^{2}\right), C$ is the average coupling coefficient, $v_{0}$ is the plate convergence rate $(=7.2 \mathrm{~cm} / \mathrm{yr}), S$ is the area of fault (green rectangle in Fig. 2, $=9.1 \times 10^{10} \mathrm{~m}^{2}$ ), and $\dot{M}_{\mathrm{o}}$ is the seismic moment release rate in the interseismic period that is estimated from observation during the period 1926 to March $2011\left(=3.2 \times 10^{19} \mathrm{~N} \mathrm{~m} / \mathrm{yr}\right)$. Here, we used the JMA catalogue (depth $<65 \mathrm{~km}, M>6$ ) and the seismic moment was calculated from the magnitude using the relationship of Hanks and Kanamori (1979). The interseismic period $(T)$ corresponds to the recurrence interval of the $M 9$ earthquake if the same processes repeat. The gray area surrounded by solid lines in Fig. 3 shows the relationship between the average coupling coefficient in the source area $(C)$ and the length of the interseismic period $(T)$ from Eq. (3). The lower limit corresponds to an afterslip moment $\left(M_{\mathrm{o}}^{\mathrm{a}}\right)$ of $0.2 M_{\mathrm{o}}^{\mathrm{c}}$ and the upper limit corresponds to $1.0 M_{\mathrm{o}}^{\mathrm{c}}$. The gray area bordered by dashed lines in Fig. 3 shows the averaged coupling coefficient in the green rectangle in Fig. 2. The upper limit corresponds to the case which assumes that the area with no small repeating earthquakes (gray areas in Fig. 2) is $100 \%$ coupled and the lower limit corresponds to the case in which we assign the minimum coupling coefficient to the area with no repeating 
earthquake data. The minimum coupling coefficient at each interseismic period was not zero, but calculated from the coseismic slip amount at each point $(D)$, the length of the interseismic period and the plate convergence rate. This is because, although we don't know the coupling coefficient in the area with no small repeating earthquakes, the coseismic slip at each point shows that the coupling coefficient cannot be zero. Therefore, we take the minimum coupling coefficient to be $D /\left(T \cdot v_{0}\right)$. Here, $D$ is the coseismic slip amount of the 2011 Tohoku earthquake for each point estimated by Iinuma et al. (2011) (contour in Fig. 2) and if $D /\left(T \cdot v_{0}\right)$ is larger than 1 , we used 1 for the value. The intersection of the $C-T$ relationship and the range of the coupling coefficient in this study shows the probable range of the averaged coupling coefficient and the length of the interseismic period (area $a-b-c-d$ in Fig. 3). It shows that the slip deficit for the 2011 Tohoku earthquake accumulated over a period of about $260-880$ years and that the average interseismic coupling coefficient is $0.5-0.8$.

The averaged interplate coupling from GPS data analysis in 1997-2001 by Suwa et al. (2006) for the same area (green rectangle in Fig. 2) is 0.83 and is close to our upper limit. A larger coupling coefficient, a larger plate convergence rate $\left(v_{0}\right)$, a smaller afterslip moment $\left(M_{\mathrm{o}}^{\mathrm{a}}\right)$, and a smaller seismic moment release rate in the interseismic pe$\operatorname{riod}\left(\dot{M}_{\mathrm{o}}\right)$ tend to reduce the longest interseismic period, and vice versa. Tsunami deposit data show a recurrence interval of 400-1300 years for great tsunamigenic earthquakes in this area (e.g., Minoura and Nakaya, 1991; Sawai et al., 2007). Apparently our estimation relies on many assumptions but it overlaps with the relatively-shorter part of the range estimated by the tsunami deposit.

\section{Hierarchical Structure of Asperities}

Hierarchical, or fractal, asperities have been proposed to explain various seismic activities on a fault (e.g., Seno, 2003; Hori and Miyazaki, 2010). The prior occurrence of $M \sim 7$ interplate earthquakes in the 2011 slip area shows that the asperities of the 2011 Tohoku earthquake have a hierarchical, or fractal, structure. A similar hierarchical asperity structure was observed in the off-Kamaishi repeating earthquake sequence in the same subduction zone, although the rupture area was very small $(\sim 1 \mathrm{~km}$, Matsuzawa et al., 2002; Uchida et al., 2007). In the off-Kamaishi sequence, earthquakes with magnitudes of less than $\sim 3.5$ occur multiple times in the slip areas of the $M \sim 4.9$ mainshocks (Uchida et al., 2007). However, the cumulative slip due to these smaller repeating earthquakes is small (10-30\%) compared to the slip due to the mainshock sequence of $M \sim 4.9$. The occurrence of earthquakes in the slip area of the mainshock and the cumulative slip of small repeating earthquakes for both the 2011 Tohoku earthquake and the off-Kamaishi sequence show that the asperities are not fully coupled and undergo aseismic slip in the interseismic period. Figure 4 schematically shows hierarchical structured asperities in the study area. The difference between a simple asperity (e.g., Uchida et al., 2003) and a hierarchical structured asperity is that the asperities have internal structures. Figure 4 shows the large asperity (blue area) that ruptured in the 2011 Tohoku earthquake and other smaller as-

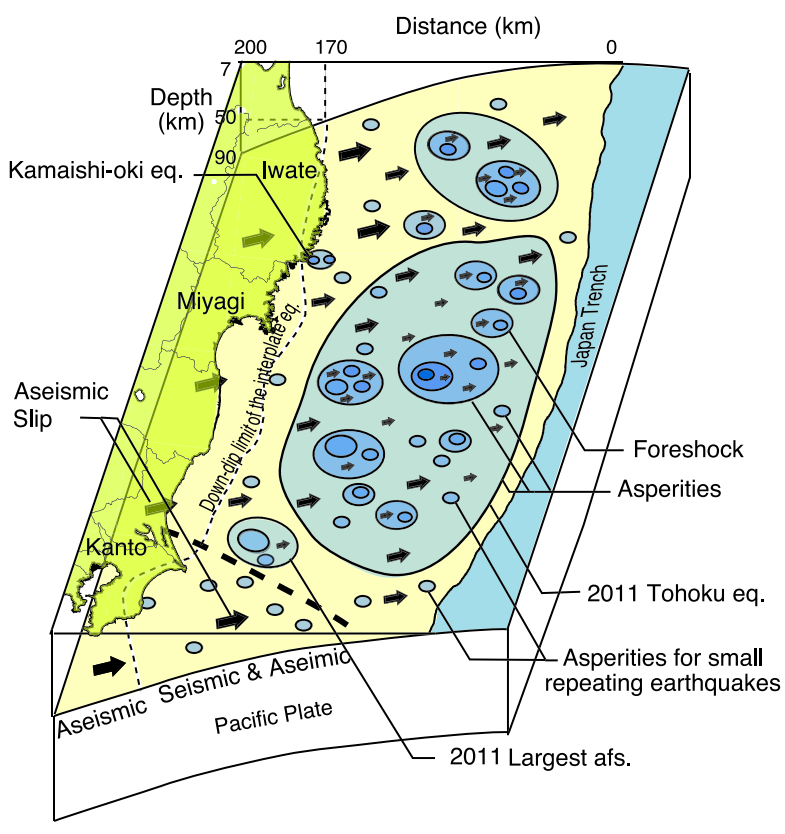

Fig. 4. Schematic figure showing the distribution of the hierarchical structured asperities at Tohoku. The circles show asperities that have internal structures. The arrows indicate aseismic slip. The dashed bold line shows the NE limit of the Philippine Sea plate and the dashed thin line shows the down-dip limit of the interplate earthquake. The area between the down-dip limit and the Japan trench has both seismic and aseismic slip.

perities. It also includes the asperities for the foreshock, the largest aftershock, the off-Kamaishi earthquake and small repeating earthquakes. Aseismic slip (arrows) in an asperity concentrates stress to internal smaller asperities due to a local difference of slip deficit (the difference of the arrow length inside and outside of the asperity) and enables the occurrence of an earthquake in a rupture area of an asperity. Therefore, the slip rate at a small asperity in a larger asperity, in the period between the earthquakes rupturing the larger asperity, becomes smaller than in the case that the small asperity is not located within a larger asperity (Fig. 4). The slip rate of these small asperities corresponds to the coupling coefficient shown in Fig. 2. The off-Kanto and the landward side of the off-Iwate area have a relatively sparse density of large asperities and a higher aseismic slip rate (lower coupling), and the area where the large 2011 Tohoku earthquake's asperity is located has a relatively high density of asperities and a smaller aseismic slip rate (higher coupling).

An awareness of the presence of higher-order asperities before their rupture is important from the perspective of earthquake hazard mitigation. Very low-slip-rate asperities (repeating earthquakes) that were observed both in the off-Kamaishi and the 2011 Tohoku earthquakes (repeating earthquakes in the red areas in Fig. 2) may indicate the existence of higher-order asperities. The slip property in the hierarchical asperity may also indicate the existence of higher-order asperities. The afterslip was found to be not so large for the 2005 Miyagi-oki earthquake $(M 7.2)$ that occurred in the source area of the 2011 Tohoku earthquake (Uchida et al., 2006). The region around the 2005 earthquake (black star in Fig. 2) is considered to be strongly 
coupled (Fig. 2). This also suggests that no large afterslip occurred after that, and that the occurrence of a $M \sim 7$ earthquake in our analysis period would not have a major impact on the degree of coupling. In the hierarchical asperity model, the afterslip will be limited in the larger asperity in which the smaller asperity is located. The afterslip may also be inhibited by the nearby asperity in the same hierarchal level. It is possible that the spatial-temporal pattern of afterslip may also be a useful indicator for the existence of a larger asperity which encompasses small asperities and minor earthquakes.

\section{Conclusions}

The spatial distribution of interplate coupling along the Japan Trench was investigated based on small repeating earthquake data. The number of small repeating earthquake groups in areas of large coseismic slip during the 2011 Tohoku earthquake is relatively small, which probably indicates that strong coupling existed in the area before the large event occurred. The interplate coupling coefficient in the coseismic slip area was found to be high $(\geq 0.5)$, and this area seems to be bounded by weakly-coupled regions to the south (south of the NE limit of the PHS) and to the north of the coseismic slip area. This estimation, and the occurrence of the $M 9.0$ earthquake, suggest that the seismic coupling in the area was stronger than previously thought. A high coupling coefficient is estimated, even near the trench, which could act as the source of the large tsunami which accompanied the present earthquake. The coupling coefficient in the coseismic slip area shows that some of the slip deficit was released aseismically but some part of the relative plate motion was accumulated in the region. The slip deficit which contributed to the 2011 Tohoku earthquake was estimated to have accumulated during a period of 260-880 years from the average coupling coefficient in the source area $(0.5-0.8)$, the interseismic moment release rate, the seismic moment of the 2011 earthquake and the assumed afterslip of the 2011 earthquake. The asperities for the 2011 Tohoku earthquake overlap with the source areas of previous $M \sim 7$ earthquakes and such $M \sim 7$ earthquakes are not characteristic earthquake in the area. The hierarchical structure of asperities may be the key to understanding huge earthquakes that encompass several smaller asperities.

Acknowledgments. We thank T. Iinuma for providing the slipdistribution data for the 2011 Tohoku earthquake, S. Hirahara and T. Nakayama for their management of the repeating earthquake data, and A. Hasegawa, N. Umino, S. Miura and R. Hino for fruitful discussions. We also thank the editor K. Yomogida, the reviewer J. Hardebeck, and an anonymous reviewer, for their thoughtful comments. This work was supported in part by the Global COE Program, 'Global Education and Research Center for Earth and Planetary Dynamics' at Tohoku University. The figures were drawn using the Generic Mapping Tools software (Wessel and Smith, 1995).

\section{References}

Fujii, Y., K. Satake, S. Sakai, M. Shinohara, and T. Kanazawa, Tsunami source of the 2011 off the Pacific coast of Tohoku Earthquake, Earth Planets Space, 63, this issue, 815-820, 2011.

Hanks, T. C. and H. Kanamori, A moment magnitude scale, J. Geophys. Res., 84, 2348-2350, 1979.
Hashimoto, C., A. Noda, T. Sagiya, and M. Matsu'ura, Interplate seismogenic zones along the Kuril-Japan trench inferred from GPS data inversion, Nature Geosci., 2, 141-144, 2009.

Hori, T. and S. Miyazaki, Hierarchical asperity model for multiscale characteristic earthquakes: a numerical study for the off-Kamaishi earthquake sequence in the NE Japan subduction zone, Geophys. Res. Lett., 37, L10304, doi:10.1029/2010GL042669, 2010.

Igarashi, T., T. Matsuzawa, N. Umino, and A. Hasegawa, Spacial distribution of focal mechanisms for interplate and intraplate earthquake associated with the subducting Pacific plate beneath the northeastern Japan arc: A triple-planed deep seismic zone, J. Geophys. Res., 106, 21772191, 2001.

Iinuma, T., M. Ohzono, Y. Ohta, and S. Miura, Coseismic slip distribution of the 2011 off the Pacific coast of Tohoku Earthquake (M 9.0) estimated based on GPS data-Was the asperity in Miyagi-oki ruptured?, Earth Planets Space, 63, this issue, 643-648, 2011.

Maeda, T., T. Furumura, S. Sakai, and M. Shinohara, Significant tsunami observed at ocean-bottom pressure gauges during the 2011 off the Pacific coast of Tohoku Earthquake, Earth Planets Space, 63, this issue, 803-808, 2011.

Matsuzawa, T., T. Igarashi, and A. Hasegawa, Characteristic smallearthquake sequence off Sanriku, northeastern Honshu, Japan, Geophys. Res. Lett., 29, doi:10.1029/2001GL014632, 2002.

Minoura, K. and S. Nakaya, Traces of tsunami preserved in inter-tidal lacustrine and mash deposits: some examples from northeast Japan, $J$. Geol., 99, 265-287, 1991.

Nadeau, R. M. and L. R. Johnson, Seismological studies at Parkfield VI: Moment release rates and estimates of source parameters for small repeating earthquakes, Bull. Seismol. Soc. Am., 88, 790-814, 1998.

Nishimura, T., T. Hirasawa, S. Miyazaki, T. Sagiya, T. Tada, S. Miura, and K. Tanaka, Temporal change of interplate coupling in northeastern Japan during 1995-2002 estimated from continuous GPS observations, Geophys. J. Int., 157, 901-916, 2004.

Oleskevich, D. A., R. D. Hyndman, and K. Wang, The updip and downdip limits to great subduction earthquakes: Thermal and structural models of Cascadia, south Alaska, SW Japan, and Chile, J. Geophys. Res., 104, 14,965-14,991, 1999.

Pacheco, J. F., L. R. Sykes, and C. H. Scholz, Nature of seismic coupling along simple plate boundaries of the subduction type, J. Geophys. Res., 98, 14,133-14,159, 1993.

Peterson, E. T. and T. Seno, Factors affecting seismic moment release rates in subduction zones, J. Geophys. Res., 89, 10,233-10,248, 1984.

Sawai, Y., M. Shishikura, Y. Okamura, K. Takada, T. Matsu'ura, T. T. Aung, J. Komatsubara, Y. Fujii, O. Fujiwara, K. Satake, T. Kamataki, and N. Sato, A study on paleotsunami using handy geoslicer in Sendai Plain (Sendai, Natori, Iwanuma, Watari, and Yamamoto), Miyagi, Japan, Ann. Rep. Active Fault Paleoearthq. Res., No. 7, 47-80, 2007.

Sella, G. F., T. H. Dixon, and A. Mao, REVEL: A model for recent plate velocities from space geodesy, J. Geophys. Res., 107(B4), 2081, doi:10.1029/2000JB000033, 2002.

Seno, T., Fractal asperities, invasion of barriers, and interplate earthquakes, Earth Planets Space, 55, 649-665, 2003.

Suwa, Y., S. Miura, A. Hasegawa, T. Sato, and K. Tachibana, Interplate coupling beneath NE Japan inferred from three dimensional displacement fields, J. Geophys. Res., 111, B04402, doi:101029/2004JB003203, 2006.

Uchida, N., T. Matsuzawa, A. Hasegawa, and T. Igarashi, Interplate quasistatic slip off Sanriku, NE Japan, estimated from repeating earthquakes, Geophys. Res. Lett., 30(15), doi:10.1029/2003GL017452, 2003.

Uchida, N., T. Matsuzawa, S. Hirahara, and A. Hasegawa, Small repeating earthquakes and interplate creep around the 2005 Miyagi-oki earthquake (M7.2), Earth Planets Space, 58(12), 1577-1580, 2006.

Uchida, N., T. Matsuzawa, W. L. Ellsworth, K. Imanishi, T. Okada, and A. Hasegawa, Source parameters of a M4.8 and its accompanying repeating earthquakes off Kamaishi, NE Japan-implications for the hierarchical structure of asperities and earthquake cycle, Geophys. Res. Lett., 34, doi:10.1029/2007GL031263, 2007.

Uchida, N., J. Nakajima, A. Hasegawa, and T. Matsuzawa, What controls interplate coupling?: Evidence for abrupt change in coupling across a border between two overlying plates in the NE Japan subduction zone, Earth Planet. Sci. Lett., 283, 111-121, 2009.

Wessel, P. and W. H. F. Smith, New version of the Generic Mapping Tools released, Eos Trans. AGU, 76, 329, 1995.

N. Uchida (e-mail: uchida@aob.gp.tohoku.ac.jp) and T. Matsuzawa 